\title{
EMERGÊNCIAS E REGRAS SANITÁRIAS EM TEMPOS DE CORONAVÍRUS Uma análise entre o Brasil e o México
}

Emergencies and Sanitary Rules in Coronavirus Times: an Analysis between Brazil and Mexico

\author{
Amalia Patricia Cobos Campos $^{1}$, Janaína ReCKziegel ${ }^{2}$ \\ ${ }^{1}$ Universidad Autónoma de Chihuahua, México \\ ${ }^{2}$ UNOESC, Brasil
}

\section{KEY WORDS}

Bioethics

Brazil and Mexico

Coronavirus

Sanitary Rules

Right to health
ABSTRACT

The present study has the theme of global health emergencies, dealing especially with the role of the National Health Surveillance Agency in Brazil and the Secretariat of Health in Mexico in the current situation of the Coronavirus. In this sense, actions at the global level to combat global health emergencies and the treatment they have received in the country are discussed. For that, we used a qualitative methodology, with bibliographic and normative research. As a result, it is clear that although there are international regulations in the fight against emergencies, Brazil and Mexico do not have adequate legislation, having created only emergency regulations.
PALAVRAS-CHAVE

Bioética

Brasil e México

Coronavírus

Regras Sanitárias

Direito à Saúde
RESUMO

O presente estudo tem como tema as emergências sanitárias globais, tratando especialmente do papel da Agência Nacional de Vigilância Sanitária no Brasil e a Secretaria da Saúde no México na situação atual de ocorrência do Coronavírus. Nesse sentido, discutem-se as ações a nível mundial no combate as emergências sanitárias globais e o tratamento que estas tem recebido no país. Para tanto utilizou-se de metodologia qualitativa, com pesquisa bibliográfica e normativa. Como resultado percebe-se que apesar de haver regulamentação internacional no combate as emergências, o Brasil e o México, não possui legislação adequada, tendo sido criada apenas regulamentação emergencial.

Recebido: 23/06/2020

Aceite: 04/01/2021

\section{GLOBAL KNOWLEDGE}




\section{Introdução}

$\mathrm{E}$ ste artigo tem como tema a questão das emergências sanitárias globais. Este assunto tem adquirido importância, pois tem se percebido que um fato ocorrido em uma parte do planeta tem repercussões para todo o mundo. Nesse sentido, o objetivo no combate as emergências sanitárias é evitar que uma doença se espalhe e saia daquele primeiro local de ocorrência.

Questiona-se o papel que os Órgãos da Saúde têm tido nesse processo, especialmente a Vigilância Sanitária, que tem atuação nessa área, no Brasil e a Secretaria da Saúde no México. Há uma regulamentação adequada para este tipo de situação nos países? A regulamentação internacional é suficiente para atender essas situações? Para responder estas questões, tomase como base o caso do Coronavírus, pois é o mais recente declarado pela Organização Mundial da Saúde. Para tanto, foi utilizada a metodologia qualitativa, tendo como base de dados a pesquisa bibliográfica e normativa.

Construi-se o texto da seguinte forma: Inicialmente aborda-se o Sistema Nacional de Vigilância Sanitária, situando a Agência Nacional de Vigilância Sanitária e apresentando suas principais funções e no México a Secretaria da Saúde. $\mathrm{Na}$ sequência apresentam-se as emergências globais, discutindo-se as principais medidas a serem tomadas no caso de ocorrência destas e a legislação pertinente, destacando-se a ocorrência do Coronavírus. Após aborda-se o papel da Vigilância Sanitária no enfrentamento as emergências globais, especialmente no que se relaciona ao Coronavirus, apresentando-se os principais protocolos e planos que estão sendo adotados, no Brasil e no México. Diante disso, discute-se na sequência os limites de atuação frente as emergências globais, destacando-se os limites legislativos, de avaliação e notificação dos pacientes.

Aborda-se-a a questão da dignidade humana, que possui relação direta com a questão da saúde. Nesse caso, verifica-se que a população tem o direito de ter garantida a proteção contra as emergências em saúde pública. No entanto, tal proteção não pode contrariar princípios fundamentais, em especial o princípio universal da dignidade humana.

Percebe-se, que as emergências sanitárias internacionais estarão cada vez mais presentes. Apesar da existência de regulamentação internacional a este respeito, bem como, de protocolos criados no Brasil e no México para seu atendimento, ainda é preciso avançar em debates a respeito da criação de legislação adequada. Tal legislação não deve servir apenas para o momento em que tais doenças vierem a ocorrer, mas de ser formulada antecipadamente, preventivamente e com maior amplitude. Nesse sentido, é necessário que sejam observados princípios fundamentais, em especial o princípio da dignidade humana.

\section{O Brasil e o Sistema Nacional de Vigilância Sanitária}

Foi definido por meio da Lei 9782/1999, o Sistema Nacional de Vigilância Sanitária que também criou a Agência Nacional de Vigilância Sanitária - ANVISA. 0 art. 1 o desta lei afirma que o Sistema Nacional de Vigilância Sanitária, compreende as ações capazes de eliminar, diminuir ou prevenir riscos à saúde e de intervir nos problemas sanitários decorrentes do meio ambiente, da produção e circulação de bens e da prestação de serviços de interesse da saúde, abrangendo o controle de bens de consumo e de prestação de serviços (Brasil, 1999).

As atividades de vigilância sanitária surgiram da necessidade de proteção da população em decorrência da propagação de doenças transmissíveis nos agrupamentos urbanos, a fim de eliminar situações de risco à saúde. Portanto, seus métodos de intervenção se direcionam ao fortalecimento da sociedade e da cidadania, para promoção de saúde e prevenção de agravos (Oliveira \& Cruz, 2015). Integra a saúde coletiva, como campo de conhecimento e de práticas e desenvolve ações no sistema de saúde, regulação sanitária das atividades relacionadas ao ciclo produção/consumo de bens e serviços da esfera privada e pública (Silva, Costa \& Lucchese, 2018).

Percebe-se que a atuação da Vigilância Sanitária é abrangente, pois tem responsabilidade no controle de processos dos bens que se relacionam direta e indiretamente 
com a saúde. E dentre as ações executadas pela vigilância sanitária, têm-se as ações preventivas voltadas a evitar o desenvolvimento de doenças específicas (Silva, Costa \& Lucchese, 2018). Nessa área localiza-se a atuação relacionada as emergências globais que serão abordadas no item quatro deste texto.

\section{0 México e a Secretaria da Saúde}

No ordenamento jurídico mexicano, neste ponto assemelhado ao brasileiro, possui uma Carta Magna que traça direitos fundamentais à vida no país. Em seu artigo 4o, impõe ao Estado o dever de garantia a saúde de sua população1(México, 1917). No que seria o inciso XVI, alínea b, do art. 73 da Constituição, obriga que, em caso de epidemias ou eminência de graves doenças no país, deverá imediatamente a Secretaria da Saúde determinar as medidas preventivas necessárias a serem sancionadas pelo Presidente para o caso específico²(México, 1917) o mesmo se encontra no artigo 181 da Ley General de Salud ${ }^{3}$ (México, 1984) além da previsão de vacinação, como responsabilidade da Secretaria de Saúde, nos casos de epidemias graves ${ }^{4}$, (México, 1984) no entanto, obviamente, sem aplicação neste momento ao Covid. No mesmo sentido, o México faz parte de diversos tratados internacionais como Declaração Universal dos

\footnotetext{
${ }^{1}$ Artículo 4o [...]Toda persona tiene derecho a la protección de la salud. La Ley definirá las bases y

modalidades para el acceso a los servicios de salud y establecerá la concurrencia de la

Federación y las entidades federativas en materia de salubridad general, conforme a lo que

dispone la fracción XVI del artículo 73 de esta Constitución.

${ }^{2}$ Artículo 73, XVI, b En caso de epidemias de carácter grave o peligro de invasión de enfermedades

exóticas en el país, la Secretaría de Salud tendrá obligación de dictar inmediatamente las medidas preventivas indispensables, a reserva de ser después sancionadas por el Presidente de la República.

3 Artículo 181. En caso de epidemia de carácter grave, peligro de invasión de enfermidades transmisibles, situaciones de emergencia o catástrofe que afecten al país, la Secretaría de Salud dictará inmediatamente las medidas indispensables para prevenir y combatir los daños a la salud, a reserva de que tales medidas sean después sancionadas por el Presidente de la República.

${ }^{4}$ Artículo 408.- Las autoridades sanitarias competentes ordenarán la vacunación de personas como medida de seguridad, en los siguientes casos: II. En caso de epidemia grave.
}

Direitos Humanos, Convenção Americana sobre Direitos Humanos e Pacto Internacional sobre Direitos Econômicos, Social e Cultural. Ainda, tem-se que a Lei Geral de Saúde, incumbe à Secretaria da Saúde o gerenciamento das campanhas contra as doenças que ameacem a população, neste caso, o Covid-19,(México, 2020) e o Plano Nacional de Desenvolvimento vigente prevê impossibilidade de negar o direito à saúde, principalmente aos mais vulneráveis.

\section{Emergências Sanitárias Globais em Saúde Pública e o Coronavírus}

Começou as discussões sobre o tema saúde global nos anos de 1990. Isso porque se tomou consciência de que uma doença que tenha aparecido em um local pode ter repercussões mundiais, como um potencial ameaça à população mundial ou à segurança nacional de outros países (Ventura, 2016).

Em vista a crescente preocupação com a ocorrência de doenças com elevada possibilidade de disseminação pelo mundo, a Organização Mundial de Saúde formulou um instrumento, em 2005 , que traz as diretrizes a serem aplicadas no caso de uma emergência sanitária de impacto global. Este instrumento é o Regulamento Sanitário Internacional (RSI), que estabelece procedimentos para proteção contra a disseminação internacional de doenças. No entanto, esta não é a primeira versão do documento, já que anteriormente havia sido adotado durante a $4^{\underline{a}}$ Assembleia Mundial da Saúde, em 1951, o primeiro código internacional. Porém o primeiro regulamento não abordava todas as possibilidades de emergências globais, seu foco eram medidas para prevenir a disseminação de doenças infecciosas (Brasil, 2009).

Nota-se que o RSI de 2005 está atualmente em vigor nos 193 países signatários da OMS e tem por objetivo impedir a disseminação internacional de doenças, controlar e dar resposta de saúde pública proporcional e restrita aos riscos, evitando interferências desnecessárias ao tráfego e comércio internacional (Sampaio \& Schütz, 2016). O RSI ainda dispõe das características de uma notificação e afirma que cada país deverá avaliar 
os eventos ocorridos em seu território, utilizando-se de instrumentos de decisão. Qualquer potencial de emergência sanitária deverá ser notificada à OMS no prazo de vinte e quatro horas (Brasil, 2009).

$\mathrm{Na}$ avaliação dos eventos ocorridos e pela utilização dos instrumentos de decisão, a direção geral da OMS, independente do consentimento dos Estados, pode declarar uma Emergência de Saúde Pública de Importância Internacional (ESPII). Esta declaração é baseada na opinião do Comitê de Emergências constituído por especialistas independentes, escolhidos conforme seu campo de competência e da experiência que corresponder ao evento em andamento (Brasil, 2009).

Verificou-se que a primeira ESPII declarada pela OMS foi em 2009 e se referiu a Gripe A (H1N1). A segunda declaração ocorreu em 2014 e se referia ao poliovírus, a terceira declaração se referiu ao Ebola, em agosto de 2014 e a quarta ocorreu em 2016, referente ao vírus Zika (Sampaio \& Schütz, 2016). Portanto a declaração relacionada ao Cornavírus é a quinta que ocorre após a criação do novo RSI.

Sobre o Coronavírus, o mesmo pertence a uma grande família de vírus que provocam doenças em seres humanos e animais. Em humanos, vários coronavírus são conhecidos por causar infecções respiratórias que vão do resfriado comum a doenças mais graves, como síndrome respiratória do Oriente Médio (MERS) e Síndrome Respiratória Aguda Grave (SARS).

O coronavírus mais recentemente descoberto causa a doença COVID-19 (Chen, Horby, Hayden \& Gao, 2020). e os primeiros casos do novo Coronavírus ocorreram em Wuhan, Província de Hubei na China, em dezembro de 2019 e Janeiro de 2020. Inicialmente acreditava-se em contaminação zoonótica, que teria ocorrido no mercado de frutos do mar, mas após percebeu-se a ocorrência de transmissão de pessoa a pessoa, por meio de gotículas (Brasil, 2009). Os sinais comuns da infecção são sintomas respiratórios, febre, tosse, dificuldade para respirar. Nos casos mais severos, a infecção pode causar pneumonia, síndrome respiratória severa, insuficiência renal e até mesmo a morte (Qun Li et al., 2020).

No Brasil, as primeiras ações em relação ao Coronavírus, ocorreram em 22 de janeiro de
2020, com a ativação do Centro de Operações de Emergência em Saúde Pública (COE-COVID-19), do Ministério da Saúde (MS) coordenado pela Secretaria de Vigilância em Saúde (SVS), com o objetivo de nortear a atuação do MS na resposta à possível emergência de saúde pública, buscando uma atuação coordenada no âmbito do SUS (Brasil, 2020).

O México no dia 24 de março de 2020, foi publicado no Diário Oficial o acordo que define as diretrizes ao enfrentamento do SARS-CoV2 (COVID-19). Na segunda quinta-feira de 2020, dia 09 de janeiro, o governo mexicano já tomava medidas de resposta ao Covid-19. Entre elas, aviso de viagem, acompanhamento das atualizações da mídia e identificação de passageiros vindos da China como suspeitos. $\mathrm{Na}$ semana seguinte, o Instituto de Diagnóstico y Referencia Epidemiológicos (Indre), em tradução livre, Instituto de Referência e Diagnósticos Epidemiológicos, desenvolveu protocolos de acordo com o sugerido pela Organização Mundial da Saúde. Na semana seguinte, foi editado um aviso epidemiológico orientando quanto à identificação dos suspeitos e atitudes preventivas. 0 protocolo envolvia a coleta de amostra, envio para o INDRE e o acompanhamento e mapeamento dos contatos do examinado (Secretaria de Salud, 2019a) (Secretaria de Salud, 2020). Em publicação de 30 de janeiro de 2020, o governo federal mexicano disse que, em que pesasse não haver casos no país, já se trabalhava em um plano de preparação e resposta, antes mesmo da OMS o considerar uma emergência de saúde pública internacional.

No dia 3 de fevereiro de 2020, o Ministério da Saúde declarou Emergência de Saúde Pública de Importância Nacional (ESPIN) em decorrência da infecção humana pelo novo Coronavírus (COVID19), por meio da Portaria MS $\mathrm{n}^{\circ} 188$, e conforme Decreto $\mathrm{n}^{\circ}$ 7.616, de 17 de novembro de 2011 (Ventura, 2016). Em 11 de março de 2020, a Organização Mundial da Saúde classificou a Doença pelo Coronavírus 2019 (COVID-19) como uma pandemia. Isso significa que o vírus está circulando em todos os continentes e há ocorrência de casos oligossintomáticos, o que dificulta a identificação (World Health Organization, 2020). 
Os fatos e conhecimentos sobre o novo Coronavírus (COVID-19) disponíveis são limitados, havendo muitas incertezas no modo exato de transmissão e os possíveis reservatórios. As taxas de letalidade, mortalidade e transmissibilidade não são definitivas e estão subestimadas ou superestimadas. As evidências epidemiológicas e clínicas ainda estão sendo descritas e a história natural ainda está sendo construída (Chen, Horby, Hayden \& Gao, 2020). Portanto ainda é um cenário de incertezas. Até o momento não há tratamento especifico para a doença e a maioria das pessoas se recupera por meio de cuidados, especialmente hospitalares.

Os objetivos estratégicos da Organização Mundial da Saúde em relação ao coronavírus são: limitar a transmissão pessoa a pessoa; identificar, isolar e cuidar precocemente dos pacientes; identificar e reduzir a transmissão de origem animal; abordar incógnitas sobre a gravidade clínica, extensão da transmissão e infecção, opções de tratamento e diagnóstico, terapêuticas e vacinas; comunicar informações críticas de risco e eventos a todas as comunidades e combater a desinformação; minimizar o impacto social e econômico por meio de parcerias multisetoriais. Estes objetivos podem ser alcançados através de uma combinação de medidas de saúde pública, como identificação rápida, diagnóstico e manejo dos casos, identificação e acompanhamento dos contatos, prevenção e controle de infecções em ambientes de saúde, implementação de medidas de saúde para viajantes, conscientização na população e comunicação de risco (World Health Organization, 2020).

Nesta perspectiva, verifica-se que a Organização Mundial da Saúde apresenta um plano de ação em relação ao Coronavírus. No entanto, é necessário situar as ações tomadas pelo governo brasileiro no combate a esta emergência mundial, especialmente no que se relaciona a Vigilância Sanitária.

\section{Atuação da ANVISA - Brasil e Secretaria da Saúde - México em emergências globais}

Observou-se que o RSI determina que cada Estado deverá designar um órgão responsável para atendimento às emergências globais, que aplicará as medidas sanitárias em conformidade com o regulamento. No caso do Brasil, esta responsabilidade é da Vigilância Sanitária, do Ministério da Saúde e do Centro de Operações de Emergências (COE).

A OMS ao emitir uma declaração de ESPII, determina um conjunto de recomendações endereçadas ao público em geral e a diferentes categorias e atores, em especial aos Estados e setor de transporte. Estas recomendações permitem coordenar a resposta a doença, racionalizando meios e providências. São orientações de natureza não-vinculante e, portanto, não há previsão de sanções para os Estados que não as cumprirem (Brasil, 2009).

0 papel da Agência Nacional de Vigilância Sanitária, foi a criação do Protocolo Para Enfrentamento do COVID-19 em Portos, Aeroportos e Fronteiras, cujos principais objetivos são: definir procedimentos e fluxos para a detecção e o controle do COVID 19 em portos, aeroportos e fronteiras; estabelecer ações a serem empreendidas em áreas portuárias, aeroportuárias e fronteiriças para minimizar o risco da disseminação do COVID 19 no território nacional; proteger a saúde de passageiros, tripulantes, pessoal de solo e do público em geral nos portos, aeroportos e fronteiras; e manter o funcionamento dos portos, aeroportos e fronteiras, minimizando os impedimentos aos fluxos de passageiros, tripulantes, cargas e suprimentos procedentes do exterior (Brasil, 2020b).

Apresenta ações o plano operacional da ANVISA a serem tomadas no caso de haver um caso suspeito em uma aeronave. Há ações direcionadas a tripulação, orientações relacionadas ao comandante da aeronave, determinações para o órgão de controle de tráfego aéreo, e deveres do operador do COE. Após o estacionamento da aeronave, a regulamentação prevê a apresentação à autoridade sanitária da Declaração Geral de Aeronave (DGA). Após o pouso da aeronave há ainda outros procedimentos a serem realizados, especialmente a avaliação do paciente pela vigilância sanitária e epidemiológica. Pela avaliação dos critérios clínicos, o caso poderá ser considerado suspeito. (Brasil, 2020b). 
Após avaliar o risco a autoridade sanitária, se necessário, irá acionar o hospital de referência para possível encaminhamento do caso suspeito. No caso de voos internacionais, deverá ser autorizado o desembarque do caso suspeito e seus contactantes, momento em que será preenchido o Termo de Controle Sanitário de Viajante (TCSV) para o caso suspeito. Após será autorizado o desembarque dos demais passageiros, com preenchimento individual correto da ficha simplificada para coleta de dados dos viajantes. Os passageiros deverão ser orientados a procurar atendimento médico se apresentarem sintomas, em quinze dias. A aeronave deve então passar por inspeção sanitária, limpeza e desinfecção e os resíduos sólidos serão considerados infectantes. São adotados procedimentos semelhantes no caso de haver suspeito de coronavirus em embarcação, com algumas peculiaridades referentes ao tipo de transporte (Brasil, 2020b).

Para o transporte rodoviário, deve-se preferencialmente manter o viajante em seu assento e oferecer máscara cirúrgica aos passageiros da mesma fileira, duas fileiras à frente e duas fileiras atrás. 0 condutor deverá procurar o serviço de saúde mais próximo ou posto da Polícia Rodoviária Federal, relatando a presença do caso suspeito e de acordo com a avaliação de risco feita pela autoridade sanitária na passagem de fronteira, deverá dirigir-se ao local de estacionamento do veículo para as ações de controle sanitário (Brasil, 2020b).

São detectados como casos suspeitos os pacientes que se enquadrarem em três situações: paciente com febre e pelo menos um sinal ou sintoma respiratório (tosse, dificuldade para respirar, batimento das asas nasais, entre outros), mais histórico de viagem para área com transmissão local, de acordo com a Organização Mundial da Saúde, nos 14 dias anteriores ao aparecimento dos sinais ou sintomas. Ou então paciente com febre, pelo menos um sinal ou sintoma respiratório e contato próximo de caso suspeito para o novo coronavírus (2019-nCoV) nos 14 dias anteriores ao aparecimento dos sinais ou sintomas. Ou ainda, paciente com febre e pelo menos um sinal ou sintoma respiratório com contato próximo de caso confirmado de novo coronavírus (2019-nCoV) em laboratório nos 14 dias anteriores ao aparecimento dos sinais ou sintomas (Brasil, 2020c).

É obrigatória e imediata a notificação, devendo ser realizada pelo meio de comunicação mais rápida disponível, em até vinte e quatro horas a partir do conhecimento de caso, que se enquadre como suspeito. Após a notificação deve ser feita a identificação de contactantes, que devem ser acompanhados e monitorados em relação a apresentação de sintomas (Brasil, 2020c).

Existe ainda o Plano de Contingência Nacional para Infecção Humana pelo novo Coronavírus COVID-19, criado pelo COE, que prevê três níveis de resposta: Alerta, Perigo Iminente e Emergência em Saúde Pública. Cada nível é baseado na avaliação do risco do novo Coronavírus afetar o Brasil e seu impacto para a saúde pública (Brasil, 2020d).

0 parâmetro em resposta de alerta corresponde a uma situação em que o risco de introdução do coronavírus no Brasil seja elevado e não apresente casos suspeitos. No nível de resposta de Perigo Iminente, há uma situação em que a confirmação de caso suspeito, caso em que a União, Estados, Distrito Federal e Municípios, poderão requisitar bens e serviços, de pessoas naturais ou jurídicas, para atendimento a irrupção da endemia, conforme previsão do Capítulo IV, Seção I, Artigo 15 da Lei no 8.080 de 19 de setembro de 1990. Neste nível de resposta a estrutura do COE será ampliada com a presença de órgãos fora do setor saúde, mas que tenham relação com a resposta coordenada ao evento (Brasil, 2020d).

0 parâmetro em resposta de Emergência de Saúde Pública de Importância Nacional (ESPIN) corresponde a uma situação em que há confirmação de transmissão local do primeiro caso de Coronavírus (COVID-19), no território nacional, ou reconhecimento de declaração de Emergência de Saúde Pública de Importância Internacional (ESPII) pela Organização Mundial de Saúde (OMS). Nesse caso, há configuração para a Declaração de ESPIN, conforme Decreto no 7.616 de 17 de novembro de 2011, que dispõe sobre a declaração de Emergência em Saúde Pública de Importância Nacional - ESPIN. Este nível é dividido em duas fases: contenção e mitigação (Brasil, 2020d). 
A fase de contenção, na introdução da doença no país é uma questão de tempo e as estratégias devem ser voltadas para evitar a transmissão sustentada do vírus. Na fase de contenção, há preocupação com a compra e abastecimento de EPIs e definições para a rede de urgência e emergência, quarentena domiciliar para casos leves. Além disso, atividade de preparação e resposta devem ser revisadas e reforçadas para o atendimento de casos confirmados, com medidas de proteção adicionais e registro de informações. Nessa fase também devem ser elaborados e publicizados os Planos de Contingência dos estados, contendo dentre outras informações, a organização da rede de atenção hospitalar. Toda rede de atenção à saúde do SUS deve ser alertada para a fase, com o objetivo de sensibilizar os profissionais de saúde, para detecção de casos suspeitos, manejo adequado e reforço do uso do EPI (Brasil, 2020d).

Já a fase de mitigação tem início a partir do registro de cem casos positivos do novo coronavírus. A partir desse momento, não são realizados testes em todos os casos, apenas em casos graves em Unidade de Terapia Intensiva. As ações e medidas devem ser adotadas para evitar a ocorrência de casos graves e óbitos. Devem ser adotadas medidas já estabelecidas nos protocolos de doenças respiratórias e caso seja evidenciada a possibilidade de superação da capacidade de resposta hospitalar para atendimento de casos graves, a adaptação e ampliação de leitos e áreas hospitalares e a contratação emergencial de leitos de UTI pode ser necessária, com o objetivo de evitar óbitos (Brasil, 2020d).

No México, a Secretaria da Saúde, o que, no Brasil seria equivalente ao Ministério da Saúde, através da Subsecretaria de Promoção e Prevenção de Saúde ficaria responsável pelas ações de preparação no âmbito de comitês de segurança e saúde. Enquanto que, o Comitê, em uma tradução livre, de Segurança da Saúde ou Sanitária, aciona o Subcomitê de Doenças Emergentes, onde figuram como integrantes outros setores do governo, como Secretarias de Trabalho e Previdência Social, Turismo, Educação Pública e Comunicações e Transportes, a Petróleos Mexicanos, entre outros. Cada participante do primeiro indica um contato técnico ao subcomitê para acompanhamento da situação(Secretaria de Salud, 2019b).

Já dia 23 de março, se iniciou a Jornada Nacional de Distância Saudável, promovida pela Subsecretaria de Saúde, algo equiparado a uma política de conscientização, que orientava quanto a medidas básicas de prevenção como lavar as mãos, etiqueta respiratória, cumprimentar à distância, responsabilidade biológica, onde também se recomendou a suspensão de eventos e atividades não essenciais. 0 país ainda estava em transição da fase 1 para 2.

No dia 24, conforme o acordo acerca das medidas preventivas e mitigadoras da doença mencionado anteriormente, reforço e aplicação das medidas determinadas na Jornada, orientou que se evitasse frequentar locais movimentados os grupos de risco ${ }^{5}$, a suspensão das atividades escolares até 17 de abril, bem como das que envolvam concentração física, trânsito ou deslocamento de pessoas, a manutenção de atividades voltadas à saúde, alimentação e abastecimento, além da preservação das relações de trabalho com base na sessão B do artigo 123 da Constituição, que trata dos direitos dos trabalhadores, além da suspensão dos eventos com mais de 100 pessoas e cumprimento das medidas de higiene, como lavar as mãos (México, 2020).

Na semana seguinte, dia 30, quando o México registrou 294 confirmações e acumulava 2.160 casos de infectados pelo Covid-19, o país definiu como emergência sanitária a epidemia do Covid19. A partir daquele momento, determinou-se a suspensão de todas as atividades não essenciais nos setores públicos, privado e o que chamam de social. Nos setores essenciais, foi proibida a reunião com mais de 50 pessoas, sendo necessário, mesmo assim, a devida higienização e manutenção de distância considerada saudável. Explicitou-se o incentivo ao resguardo domiciliar definido como uma limitação voluntária de

\footnotetext{
${ }^{5}$ Adultos com mais de 65 anos de idade e grupos de pessoas em risco de desenvolver doenças graves e/ ou morrer por causa delas, mulheres grávidas ou lactantes, crianças menores de 5 anos, pessoas com deficiência, pessoas com doenças crônicas não transmissíveis (pessoas com pressão alta, pulmão, insuficiência renal, lúpus, câncer, diabetes mellitus, obesidade, insuficiência hepática ou metabólica, doença cardíaca) ou com qualquer doença ou tratamento farmacológico que gere a supressão do sistema imunológico.
} 
mobilidade, enquanto que, aos que no Brasil chamam-se grupos de risco, aplica-se uma orientação mais enfática, portanto para idosos, grávidas, doentes crônicos ou autoimunes. Desde o referido momento, cientificada foi a população que as orientações poderiam se postergar mediante novo aviso, ainda, que as medidas deveriam se aplicar com respeito aos direitos humanos e que no dia 30 de abril as secretarias e órgãos estabeleceriam as diretrizes para o retorno gradual às atividades. Como atividades essenciais entenderam-se as necessárias ao atendimento de saúde ${ }^{6}$, segurança pública e proteção, defesa da justiça e soberania nacional e atividades legislativas, setores fundamentais à economia ${ }^{7}$, programas sociais do governo e a manutenção dos serviços essenciais como água e energia elétrica (Gobierno de México, janeiro 2020).

0 portal do governo mexicano, tem disponibilizado cursos, orientações sobre saúde mental, uma página para crianças onde disponibiliza material explicativo adaptado sobre as rotinas de prevenção ao vírus, resposta de perguntas, indicação de sites e artigos científicos, dados abertos, etc. (Gobierno de México, abril 2020). Em 14 de abril, quando a mortalidade no

\footnotetext{
${ }^{6}$ Atividades clínicas, administrativo e de apoio em todo o setor da saúde, público e privado. Integrantes da teia de fornecimento, serviços e suprimentos, com ênfase em: setor farmacêutico (produção e distribuição), fabricação de suprimentos e equipamentos médicos, os envolvidos no descarte adequado de resíduos perigosos infecciosos biológicos, limpeza e higienização de unidades médicas.

7 Cobrança de impostos, distribuição e venda de energia, gás e postos de gasolina, geração e distribuição de água potável, indústria de alimentos e bebidas não alcoólicas, mercados de alimentos, supermercados, lojas de autoatendimento, mercearias e vendas de alimentos preparados; serviços de transporte de passageiros e de carga; produção agrícola, produção pesqueira e pecuária, agronegócio, produção de químicos e de limpeza; lojas de ferragens, serviços de correio, guardas em tarefas de segurança privada; creches, lares para idosos, abrigos e centros de atendimento a mulheres vítimas de violência, suas filhas e filhos; telecomunicações e mídia, serviços de emergência privados, serviços funerários e enterros, cadeia de armazenamento e frio de suprimentos essenciais); logística (aeroportos, portos e ferrovias), bem como atividades cuja suspensão possa ter efeitos irreversíveis para sua continuidade. Água potável, energia elétrica, gás, óleo, gasolina, combustível de aviação, saneamento básico, transporte público, infraestrutura hospitalar e médica de primeiro nível; entre outros que podem ser definidos nesta categoria.
}

país era de 0,26\% em relação à enfermidade, de acordo com o anteriormente mencionado subsecretário de prevenção e promoção de saúde mexicano, 40\% dos infectados com o Covid-19 já haviam se curado e que 8 a cada 10 se curam espontaneamente pelo próprio sistema imunológico, sem sequelas, em cerca de 14 dias. Também que, de acordo com estimativas, 70\% dos que se contaminassem no mundo com o vírus não teriam manifestação. Relevante que cerca de $75 \%$ da população mexicana sofre com sobrepeso e entre os maiores de 20 anos, respectivamente, $14 \%$ sofrem de diabetes e $35 \%$ de hipertensão.

Em conformidade com a Lei Orgânica da Administração Pública Federal permitindo, o Presidente Andrés Manuel López Obrador, junto à Secretaria das Relações Exteriores, buscou suprimentos médicos no exterior. Nestas compras, cita-se o exemplo da aquisição de cerca de 1 milhão de máscaras e outros itens relativos a proteção ao COVID19 (Gobierno de México, abril 2020).

\section{Limites de atuação em emergências internacionais: México e Brasil}

Caracteriza-se epidemia o quadro de identificação patológica com número superior ao esperado. Nessa classificação, há de se verificar o agente, população, momento e local em relação à quantidade de casos registrados (México, 2020). Cada país define parâmetros para o que se chamam de fases para o enfrentamento da doença.

O México faz parte de diversos tratados internacionais como Declaração Universal dos Direitos Humanos, Convenção Americana sobre Direitos Humanos e Pacto Internacional sobre Direitos Econômicos, Social e Cultural. Ainda, tem-se que a Lei Geral de Saúde, incumbe à Secretaria da Saúde o gerenciamento das campanhas contra as doenças que ameacem a população, neste caso, o Covid-19 (México, 2020) e o Plano Nacional de Desenvolvimento vigente prevê impossibilidade de negar o direito à saúde.

0 Estado Mexicano está organizado de modo que, na fase um, de preparação, não havia transmissão no país. É o período em que se atenta ao ingresso de pessoas, isolando 
potencialmente infectados e controlando a doença. $\mathrm{Na}$ fase dois, de contenção, tendo já cidadãos infectados, se praticam medidas a fim de evitar a propagação do vírus por meio da transmissão comunitária. Nesta etapa que se determina limitações quanto às aulas, viagens, eventos e manifestações, etc. servindo como período preparatório à fase três. Nessa fase, de transmissão comunitária e sustentada, ou seja, maior probabilidade de contágio e de maior expansão do vírus, quando ele circula ativamente. Por fim, a quarta fase, de recuperação, diminuindo o número de novos casos gradativamente (Cazarré, 2020). A fase três representa um risco à saturação dos hospitais e de haver milhares de contágios, mas que poderia ser mitigado se a população não visitasse espaços públicos e empresas "não essenciais" suspendessem suas atividades.

É perceptível a existência de regulamentação internacional no que se refere as emergências sanitárias pela Organização Mundial da Saúde e o México bem como o Brasil, devem observá-las. No entanto, é perceptível uma fragilização interna em ambos os países na regulamentação para emergências sanitárias.

No Brasil, muito embora exista o Decreto 7616/2011 que trata a respeito da declaração de Emergência em Saúde Pública de Importância Nacional - ESPIN e que institui a Força Nacional do Sistema Único de Saúde - FN-SUS, porém o tema ainda precisa avançar. Tal fato foi sentido no caso do Coronavírus, quando brasileiros residentes na província de Wuhan, protestaram por ajuda do governo brasileiro, para retornar ao país e não havia regulamentação adequada para lidar com a situação.

Como não havia a regulamentação adequada para agir no caso daqueles brasileiros que solicitavam ajuda do governo, rapidamente o mesmo aprovou a Lei 13.979 de 06 de fevereiro de 2020, que dispõe sobre as medidas para enfrentamento da emergência de saúde pública de importância internacional decorrente do coronavírus responsável pelo surto de 2019 (Brasil, 2020e).

A nova lei trouxe conceitos importantes, tais como o do isolamento, que é separação de pessoas doentes ou contaminadas, ou de bagagens, meios de transporte, mercadorias ou encomendas postais afetadas, de outros, de maneira a evitar a contaminação ou a propagação do coronavírus e o conceito de quarentena, que trata-se da restrição de atividades ou separação de pessoas suspeitas de contaminação das pessoas que não estejam doentes, ou de bagagens, contêineres, animais, meios de transporte ou mercadorias suspeitos de contaminação, de maneira a evitar a possível contaminação ou a propagação do coronavírus (Brasil, 2020e).

No seu artigo 3ㅜㅡ, a Lei 13.979/2020 também apresenta as medidas a serem tomadas para enfrentamento da Emergência Saúde Pública de Importância Internacional - Coronavírus, que são: isolamento, quarentena, realização compulsória de exames médicos, testes laboratoriais, coleta de amostras clínicas, vacinação e outras medidas profiláticas, tratamentos médicos específicos, estudo ou investigação epidemiológica, exumação, necropsia, cremação e manejo de cadáver, restrição excepcional e temporária de entrada e saída do País, conforme recomendação técnica e fundamentada da Agência Nacional de Vigilância Sanitária (Anvisa), por rodovias, portos ou aeroportos, requisição de bens e serviços de pessoas naturais e jurídicas, hipótese em que será garantido o pagamento posterior de indenização justa e autorização excepcional e temporária para a importação de produtos sujeitos à vigilância sanitária sem registro na Anvisa, desde que registrados por autoridade sanitária estrangeira e previstos em ato do Ministério da Saúde (Brasil, 2020e).

A legislação ainda determinou em seu art. 4 o que enquanto perdurar esta emergência de saúde pública, fica dispensada a licitação para aquisição de bens, serviços e insumos de saúde destinados ao enfrentamento do Coronavírus. 0 art. 5ㅇ ainda declara que toda pessoa deverá informar possíveis contatos com agentes infecciosos do coronavírus e se houver circulação em áreas consideradas como regiões de contaminação pelo coronavírus (Brasil, 2020e).

A presente lei possibilitou a realização da chamada "Operação Regresso", que tratou a respeito do retorno dos brasileiros repatriados de Wuhan, localizada na província de Hubei na China, desde sua saída do local até 18 dias após 
chegada ao Brasil, período total de duração da quarentena definida pelo Ministério da Saúde. Para esta operação foi emitida uma Recomendação do Ministério da Saúde e da Vigilância Sanitária, sobre os procedimentos a serem adotados no embarque, durante o voo, conexão e desembarque, bem como do período da quarentena dos brasileiros submetidos a operação (Brasil, 2020f).

Esta lei possibilitou a criação de planos de ação em relação a Vigilância em Saúde, Vigilância Sanitária e no âmbito do Ministério da Saúde. Como medida de urgência, esta legislação trouxe ações e definições relevantes, que antes não estavam previstas no Direito brasileiro. No entanto, ainda é necessária uma legislação e regulamentação mais detalhada, no tocante as ações de emergência em saúde pública.

Percebe-se a necessidade de legislação no âmbito das práticas da Agência Nacional da Vigilância Sanitária. Embora, este não seja o único campo de necessidade legislativa. A legislação necessária deve levar em conta os princípios norteadores do Sistema Único de Saúde (SUS), sendo capaz de articular ações de promoção, prevenção, recuperação e reabilitação em saúde, nas dimensões individuais e coletivas, visando à atenção integral a saúde da população (Teixeira, Costa, Viana \& Paim, 2009).

Em relação ao cuidado a ser tomado na criação de legislação específica sobre o tema, é considerar o respeito aos direitos fundamentais previstos nas leis máximas, especialmente nesses casos, pois existe grande risco de atos adotados em nome da necessidade de proteção à saúde, desrespeitarem direitos. Pois não há justificativa para proposição de leis sanitárias restritivas e coercitivas, que poderão afastar ou ignorar garantias estabelecidas na Constituição. Esta em verdade, atua como forma de segurança frente à arbítrios que possam levar a interpretações equivocadas de alguma norma jurídica gerando decisões danosas e ou constrangedoras (Teixeira, Costa, Viana \& Paim, 2009).

Existe o perigo de que leis coercitivas de liberdades, mesmo que tenham como propósito a preservação da integridade da saúde da população, possam representar ameaça a democracia. Apesar de que em situações especiais, como no caso do Coronavírus serem necessárias medidas para contenção da doença, é preciso estar atento na criação de leis que não atuem de forma a atingir princípios constitucionais, especialmente o principio da Dignidade Humana. 0 ideal é que a atuação legislativa trilhe o caminho do saber técnico aliado a democratização das informações, a fim de cumprir a proteção da saúde, sem utilizar de gesto de autoritarismo (Teixeira, Costa, Viana \& Paim, 2009).

Nota-se que além do limite legislativo, há o limite em relação a notificação da doença. Para superar tal limite é necessário que os profissionais de saúde, ao atenderem os casos suspeitos estejam sensibilizados e treinados para que não deixem de notificar. Afinal de contas, se as notificações não forem adequadamente realizadas, há risco de uma emergência de saúde pública e ocorrer uma disseminação sem controle ou cuidados necessários. Este limite também esbarra na questão da avaliação do paciente, pois para que haja notificação é fundamental que hajam protocolos de avaliação e treinamentos aos profissionais, para identificar os casos suspeitos.

Frente a tais limites é necessário que se destaque a questão do principio da Dignidade Humana, que deve estar inserido no atendimento aos pacientes vitimas de emergências em saúde pública, bem como no cuidado a população em geral, o que reporta-se a seguir.

\section{Emergência em Saúde Pública e o Princípio da Dignidade Humana}

Immanuel Kant (1974) considera que: "No reino dos fins tudo tem um preço ou uma dignidade. Uma coisa que tem um preço pode ser substituída por qualquer outra coisa equivalente; [...] o que está acima de todo preço [...], o que não admite equivalente, é o que tem uma dignidade". Diante disso, é perceptível que o ser humano é portador de dignidade, já que não pode ser tratado como objeto, tem um fim em si mesmo.

Percebe-se que a dignidade humana também é reconhecida como atributo dos indivíduos desprovidos de condições de se autogerirem, pois também possuem direito de receberem tratamento digno por sua existência. Em verdade, a dignidade humana não depende 
reconhecimento jurídico para existir, pois é um bem inato e ético, colocando-se acima das especificidades culturais e morais. Persiste mesmo naquelas sociedades em que não a respeitam, já que a sua violação evidencia afronta a capacidade de autodeterminação do ser humano e de sua própria condição de ser livre (Reckziegel, 2016).

Explica Reckziegel (Reckziegel, 2016), que quando não houver respeito à vida, à integridade física e moral do ser humano, quando não houver mínimas condições para que o individuo possa levar uma vida de modo digno, onde os poderes forem ilimitados, quando não houver reconhecimento dos direitos básicos e fundamentais dos indivíduos, a dignidade humana não está presente. 0 outro ser humano nunca deve ser colocado em desvantagem, não poderá ser tratado de modo que seja negada a importância da sua vida.

Neste viés, quando não há respeito à vida de qualquer ser humano, e nesse caso, destaca-se a questão de sua saúde, consequentemente há desrespeito ao princípio da dignidade humana. Aqui, percebe-se a necessidade de proteção à saúde da população, que tem o direito de estar livre de qualquer ameaça que possa atingir seu bem estar físico, mental e social. Portanto há necessidade da criação de estratégias que resguardem a saúde da população a fim de que seja respeitado o principio da dignidade humana.

As medidas utilizadas para resguardar a saúde da população não podem restringir direitos constitucionais básicos, já que facilmente leis arbitrárias podem contrariar o princípio da dignidade humana. Nesse caso, há o risco de os poderes tornarem-se ilimitados e de reconhecimento de direitos básicos não estarem presentes.

Nota-se que no caso de pessoas que adquirirem a doença, deve-se tomar o cuidado, de não colocá-las em desvantagem, diminuindo a importância de sua vida. Isso seria uma afronta total ao principio da dignidade humana. Afinal de contas, não é porque o individuo é portador de uma doença considerada emergência em saúde pública, que o mesmo perdeu sua condição de ser humano e portanto detentor de dignidade. Nesse caso, as ações adotadas devem ser no sentido de recuperação de sua saúde e cuidados para que não haja transmissão da doença. Já que o principio da dignidade humana tem vinculação direta com o direito à saúde.

Sarlet e Fensterseifer (Sarlet \& Fensterseifer, 2007) abordam a dimensão ambiental da dignidade humana, que contempla a qualidade de vida como um todo, inclusive do ambiente em que a vida humana se desenvolve. Tal abordagem está de acordo com a questão das doenças emergenciais, pois estas doenças tendem a diminuir a qualidade de vida. Portanto, é dever do Estado prestar ações que impeçam a disseminação destas patologias e no caso de estas ocorrerem agir de forma a evitar o máximo possível sua transmissão. Ainda, nesta dimensão, no caso de existirem pessoas contaminadas com a doença, o Estado tem dever prestacional em relação à reabilitação da saúde destes, a fim de garantir a preservação da dignidade humana.

\section{Conclusão}

Frente as emergências sanitárias de importância internacional tem ganhado muito destaque nos últimos anos. Isso ocorreu pela percepção de que uma doença presente em um local pode rapidamente ser disseminada por todo mundo. Diante disso, foram criadas regulamentações internacionais para atendimento a estas situações. Estas regulamentações vinculam o Brasil e o México, mas não são suficientes para as necessidades dos países. Por esta razão, diante da emergência do Coronavírus, rapidamente criou-se uma legislação emergencial, a fim de atender as necessidades momentâneas geradas pela doença. No entanto, esta legislação ainda é insuficiente, sendo necessária uma melhor regulamentação para atendimento as emergências internacionais que surgirem, de forma preventiva.

A legislação deve estar atenta aos princípios constitucionais, especialmente ao princípio da Dignidade Humana. Isso porque ao se refletir sobre a criação de regulamentação, deve-se levar em conta o respeito à vida de cada ser humano, seja ele ou não portador da doença. Importante ainda, é que tal regulamentação seja criada de forma crítica e técnica, com respeito a princípios e conhecimento científico, para que não se torne uma forma de ferir direitos constitucionais. 
O presente tema está em evidencia, visto que vive-se o período em que a emergência internacional Coronavírus está em crescimento exponencial. As ações tomadas em relação à doença devem ser imediatas e urgentes, com respeito aos princípios constitucionais. No entanto, é ainda necessário que se pensem sobre as novas possibilidades de emergência que ocorrerão no futuro, para que dessa forma, esteja-se preparado para seu enfrentamento.
A reflexão acerca da universalização das políticas públicas de saúde como característica da globalização neste momento é salutar. É perceptível a interação e diálogo entre os países a fim de traçar rotas para a garantia do direito social constitucional, à saúde. Neste sentido é que cabe a análise em relação às políticas de enfrentamento e regras de vigilância sanitária nos países vizinhos latino-americanos. 


\section{Referências}

Brasil (26 de janeiro de 1999). Lei 9.782. Define o Sistema Nacional de Vigilância Sanitária, cria a Agência Nacional de Vigilância Sanitária, e dá outras providências. Brasília, 27 jan. 1999. Disponível em: http://www.planalto.gov.br/ccivil_03/LEIS/L9782.htm [Acesso em 12 fev. 2020].

Brasil (2009). Agência Nacional de Vigilância Sanitária. Regulamento Sanitário Internacional - RSI 2005. Versão em português aprovada pelo Congresso Nacional por meio do Decreto Legislativo 395/2009. Disponível em: http://www.anvisa.gov.br/hotsite/viajante/Regulamento_Sanitario_Internacional_versão\%20par a\%20impressão.pdf. [Acesso em 22 fev. 2020]

Brasil (2020). Ministério da Saúde. Boletim Epidemiológico: Doença pelo Coronavírus 2019 Ampliação da Vigilância, Medidas não Farmacológicas e Descentralização do Diagnóstico Laboratorial. Disponível em: http://maismedicos.gov.br/images/PDF/2020_03_13_Boletim-Epidemiologico05.pdf. [Acesso em 24 fev. 2020]

Brasil (2020b). Agência Nacional de Vigilância Sanitária. Protocolo para enfrentamento do covid 19 em portos, aeroportos e fronteiras. Brasília. Disponível em: http://portal.anvisa.gov.br/documents/219201/4340788/Protocolo+simplificado+Coronavirus+ 06+02-revisao+final+3_diagramado2+\%281\%29.pdf/1c97fbd6-8af8-40e9-9cee-56803803c4b4. [Acesso em 25 fev. 2020].

Brasil (2020c). Novo Coronavírus. Disponível em: https://egestorab.saude.gov.br/image/?file=20200210_N_EmktCoronaVirusPopV2_92209902631 89084795.pdf. [Acesso em 01 de mar. 2020].

Brasil (2020d). Plano de Contingência Nacional para Infecção Humana pelo novo Coronavírus COVID-19. Ministério da Saúde. $\quad$ Disponível em: https://portalarquivos2.saude.gov.br/images/pdf/2020/fevereiro/13/plano-contingenciacoronavirus-COVID19.pdf. [Acesso em 05 mar. 2020].

Brasil (2020e). Lei 13979 de 06 de fevereiro de 2020. Dispõe sobre as medidas para enfrentamento da emergência de saúde pública de importância internacional decorrente do coronavírus responsável pelo surto de 2019. Brasília. Disponível em: http://www.planalto.gov.br/ccivil_03/_ato20192022/2020/Lei/L13979.htm. [Acesso em 10 de mar. 2020]

Brasil (2020f). Operação Regresso. Brasília. Disponível em: https://portalarquivos2.saude.gov.br/images/pdf/2020/fevereiro/11/operacao-regresso-11fevb.pdf. [Acesso em 25 fev. 2020]

Cazarré, M. (22 de abril de 2020). México anuncia contágio comunitário por coronavírus: fase tem surtos regionais e disseminação nacional da doença. Agência Brasil. Disponível em https://agenciabrasil.ebc.com.br/internacional/noticia/2020-04/mexico-anuncia-contagiocomunitario-por-coronavirus-no-pais. Acesso em 02 maio 2020.

Chen, W., Horby, P.W., Hayden, F. G. \& Gao, G. F. (2020). A novel coronavirus outbreak of global health concern. The Lancet, 35, pp. 470-473. Disponível em: https://www.thelancet.com/journals/lancet/article/PIIS0140-6736(20)30185-9/fulltext. [Acesso em 16 fev. 2020]

Gobierno de México (abril, 2020). Estrategia de Salud y SRE de combate al COVID-19. Disponível em: < https://coronavirus.gob.mx/2020/04/17/estrategia-de-salud-y-sre-de-combate-al-covid-19/>. Acesso em 27 abr. 2020.

Gobierno de México (janeiro, 2020). Se declara como emergencia sanitaria la epidemia generada por Covid-19. Disponível em: <https://www.gob.mx/salud/prensa/033-mexico-esta-preparado-paraenfrentar-coronavirus-2019-ncov>. Acesso em 27 abr. 2020.

Kant, I. (1974). Crítica da razão pura e outros textos filosóficos (trad. de Paulo Quintela). São Paulo: Abril Cultural.

México (1917). Constitución Política de Los Estados Unidos Mexicanos. Ciudad de México, DF. 
México (7 de fevereiro de 1984). Ley General de Salud. Lei de 07 de fevereiro de 1984. Diário Oficial Federal. Ciudad de México, DF.

México (24 de março de 2020). Acuerdo por el que se establecen las medidas preventivas que se deberán implementar para la mitigación y control de los riesgos para la salud que implica la enfermedad por el virus SARS-CoV2 (COVID-19). Diário Oficial Federal. Ciudad de México, DF. Disponível em https://www.dof.gob.mx/nota_detalle.php?codigo=5590339\&fecha=24/03/2020. Acesso em 02 maio 2020.

Oliveira, C.M. \& Cruz, M.M. (2015). Sistema de Vigilância em Saúde no Brasil: avanços e desafios. Saúde em Debate [online], 39(104), pp. 255-267. Disponível em: https://doi.org/10.1590/010311042015104038. [Acesso em 15 fev. 2020].

Qun Li et al. (2020). Early Transmission Dynamics in Wuhan, China, of Novel Coronavirus-Infected Pneumonia. The New England Journal of Medicine. Disponível em: https://www.nejm.org/doi/full/10.1056/NEJMoa2001316\#article_references. [Acesso em 22 fev. 2020]

Reckziegel, J. (2016). Dignidade humana em risco: existe limites para experiências científicas? Prismas: Curitiba.

Sampaio, J.R.C. \& Schütz, G.E. (2016). A epidemia de doença pelo vírus Ebola de 2014: o Regulamento Sanitário Internacional na perspectiva da Declaração Universal dos Direitos Humanos. Cadernos Saúde Coletiva, 24(2), pp. 242-247. DOI: https://doi.org/10.1590/1414-462X201600020184

Sarlet, I.W. \& Fensterseifer, T. (2007). Algumas notas sobre a dimensão ecológica da dignidade da pessoa humana e sobre a dignidade da vida em geral. Revista Brasileira de Direito Animal, 3, pp. 69-94.

Secretaria de Salud (2019a). 015. Acciones de preparación y respuesta ante nuevo coronavirus (2019nCoV) para la protección de la salud en México. Disponível em: https://www.gob.mx/salud/prensa/015-acciones-de-preparacion-y-respuesta-ante-nuevocoronavirus-2019-ncov-para-la-proteccion-de-la-salud-en-mexico?idiom=es. Acesso em 30 abr. 2020.

Secretaria de Salud. (2019b). 033. México está preparado para enfrentar coronavirus (2019-nCoV): si bien no se registran casos en el país, se instrumenta un Plan de Preparación y Respuesta. Disponível em: https://www.gob.mx/salud/prensa/033-mexico-esta-preparado-para-enfrentar-coronavirus2019-ncov. Acesso em 30 abr. 2020.

Secretaria de Salud. (30 de enero de 2020). Se reúne de forma extraordinaria el Comité Nacional para la Seguridad en Salud. Disponível em: https://www.gob.mx/salud/prensa/se-reune-de-formaextraordinaria-el-comite-nacional-para-la-seguridad-en-salud?idiom=es. Acesso em 30 abr. 2020.

Silva, J.A.A., Costa, E.A. \& Lucchese, G. (2018). SUS 30 anos: Vigilância Sanitária. Ciência \& Saúde Coletiva, 23(6), pp. 1953-1961. Disponível em: https://doi.org/10.1590/1413-81232018236.04972018. [Acesso em 21 fev. 2020].

Teixeira, M.G., Costa, M.C., Viana, I.; Paim, J.S. (2009). Vigilância em Saúde: É Necessária uma Legislação de Emergência? Revista de Direito Sanitário, 10(2), pp. 126-144.

Ventura, D.F.L. (2016). Do Ebola ao Zika: as emergências internacionais e a securitização da saúde global. Cadernos de Saúde Pública, 32(4). Disponível em: https://doi.org/10.1590/0102-311X00033316. [Acesso em 20 fev. 2020]

World Health Organization (2020). Coronavirus. Genebra: 2020. Disponível em: https://www.who.int/health-topics/coronavirus. [Acesso em 23 fev. 2020]. 